\title{
Chassis dynamometer for electric two wheelers
}

\author{
Muhammad Hadi Hassan ${ }^{1}$, Syazwana Sapee ${ }^{1}$, Daing Mohamad Nafiz ${ }^{1, *}$, Ahmad Fitri \\ Yusop $^{1,2}$, Mohamad Firdaus Basrawi ${ }^{1}$, and Azri Hizami Rasid ${ }^{1}$ \\ ${ }^{1}$ Faculty of Mechanical Engineering, Universiti Malaysia Pahang, 26600 Pekan, Pahang, Malaysia, \\ Phone: +6094246369; Fax: +6094246222 \\ ${ }^{2}$ Automotive Engineering Centre, Universiti Malaysia Pahang, 26600 Pekan, Pahang, Malaysia
}

\begin{abstract}
In recent years, electric two-wheelers are emerging as one of the alternatives to improve the sustainability of transportation energy and air quality, especially in urban areas. Although electric two-wheeler motorcycles are environmentally friendly, they underperform compared with gasoline two-wheelers in many respects, particularly in speed and cruise distance between refuelling and recharging. Therefore, the engine development program can be done with a dynamometer. Variables such as the shape of torque and power curves can be analyzed. Hence, this project is aimed to develop a chassis dynamometer that can be used to measure mechanical power, speed and torque, and provide a controllable load to the electric motorcycle being tested. The prototype of chassis dynamometer for electric motorcycle had been developed and performance of the chassis dynamometer was tested by using an electric bicycle to emulate the basic performance requirements of an electric motorcycle which consist of maximum speed, driving range and acceleration.
\end{abstract}

\section{Introduction}

In Malaysia, engine-powered motorcycles are famous transportation method. However, exhaust emission from gasoline engine powered motorcycles is one of the main pollution sources. As an alternative, electric two-wheelers can be a solution to the current internal combustion engine motorcycle emission issue $[1,2]$.

Although electric two-wheeler motorcycles are environmentally friendly, they underperform compared with gasoline two-wheelers in many respects. It is expected for requirements of batteries performances such as high output power density, high energy density, increased recycling usage life, shorter charging time, high energy efficiency, and minimum self-discharge rate and also maintenance-free [3-9]. The low energy density of batteries makes electric two-wheelers' performance lower compared to an internal combustion engine vehicles [10]. However, electric two-wheelers driving mileages can be improved by developing system efficiency through proper energy management [11-13].

The improvement on the engine is one of the major keys in an engine test facilities. The engine development program can be done with a dynamometer. Variables such as the shape of torque and power curves can be analyzed. The main purpose of using a dynamometer is to

\footnotetext{
*Corresponding author: daingnafiz@ump.edu.my
} 
get accurate and repeatable data on the tested engine. Dynamometer comprises of a metallic structure in which the bikes are placed through a ramp. The bike is tied to the dynamometer by the front wheel through a clamp that can be adjusted with the purpose of fitting the position of the back wheel. The rear wheel is placed over a solid knurled roller of steel that is fixed on the structure with two bearings [14].

A chassis dynamometer is used to measure torque and power delivered by the power train of a vehicle without removing the engine from the frame of the vehicle. Chassis dynamometer's structure has three main parts which consist of a roller, platform and additional frame. The roller has two purposes, first to receive the power that provided by the wheel and second, to absorb and store this energy in form of angular velocity, is to say acts of the inertial wheel. In order to achieve optimum condition roller, inertia and roller RPM must be at the peak. Nevertheless, the roller does not have to roll faster than $5000 \mathrm{rpm}$ due to mechanical limitations.

This project is aimed to develop a chassis dynamometer that can be used to measure mechanical power, speed and torque, and provide a controllable load to the electric motorcycle being tested. The prototype of chassis dynamometer for electric motorcycle had been developed and performance of the chassis dynamometer was tested by using an electric bicycle to emulate the basic performance requirements of an electric motorcycle which consist of maximum speed, driving range and acceleration.

\section{Design and fabrication of chassis dynamometer}

The platform and the rollers of the chassis dynamometer are built according to the specifications of the most electric two-wheelers. The frame for electric DC motor is fabricated according to the specification of the DC motor to make sure it can be fit in perfectly.

Firstly, a design of the platform and rollers was constructed, which has an adequate size for all electric two-wheelers. The design was done by using computer-aided engineering software which is Solidworks as shown in figure 1. Then, the static analysis study was done for safety purposed and overall rigidity of the dynamometer platform. After the suitability and availability of the material are confirmed, the platform can be fabricated accordingly. This is including the design and fabrication of the motor frame.

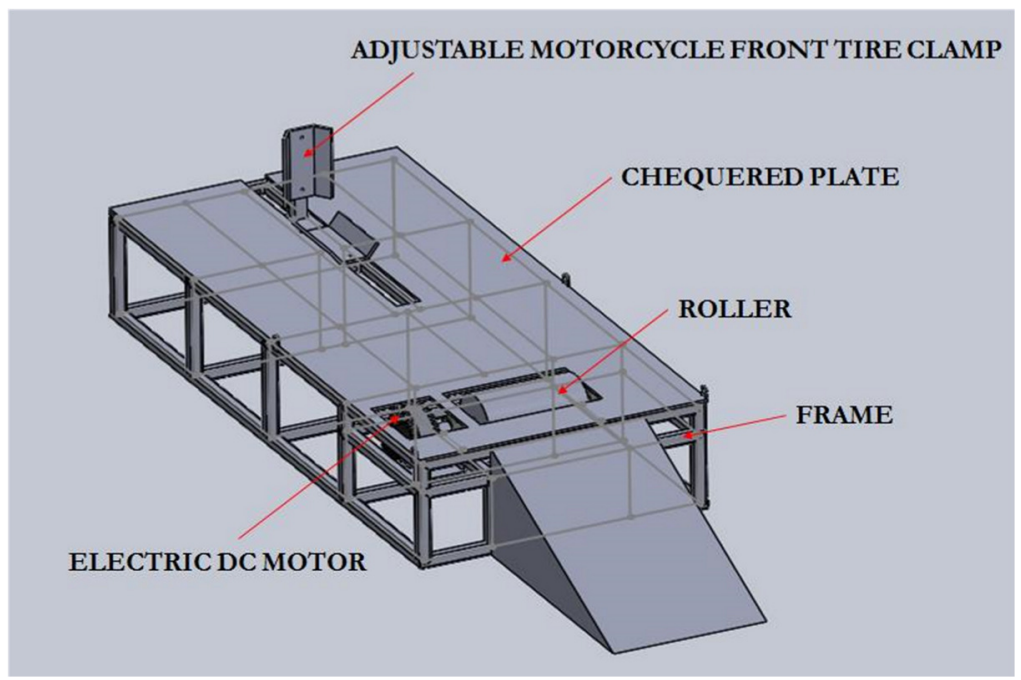

Fig. 1. Chassis dynamometer assembly modelling 
The frame was fabricated using a hollow structural square section $40 \mathrm{~mm} \times 40 \mathrm{~mm}$ welded as per design. The overall dimension of the frame is $900 \mathrm{~mm} \times 2000 \mathrm{~mm} \times 350 \mathrm{~mm}$. The platform was made using $2 \mathrm{~mm}$ mild steel sheet metal. Then, it was grinded to place the roller as shown in figure 2. Figure 3 shows the prototype of chassis dynamometer for an electric motorcycle. The chassis dynamometer then was tested by using an electric bicycle as elaborated in next section.

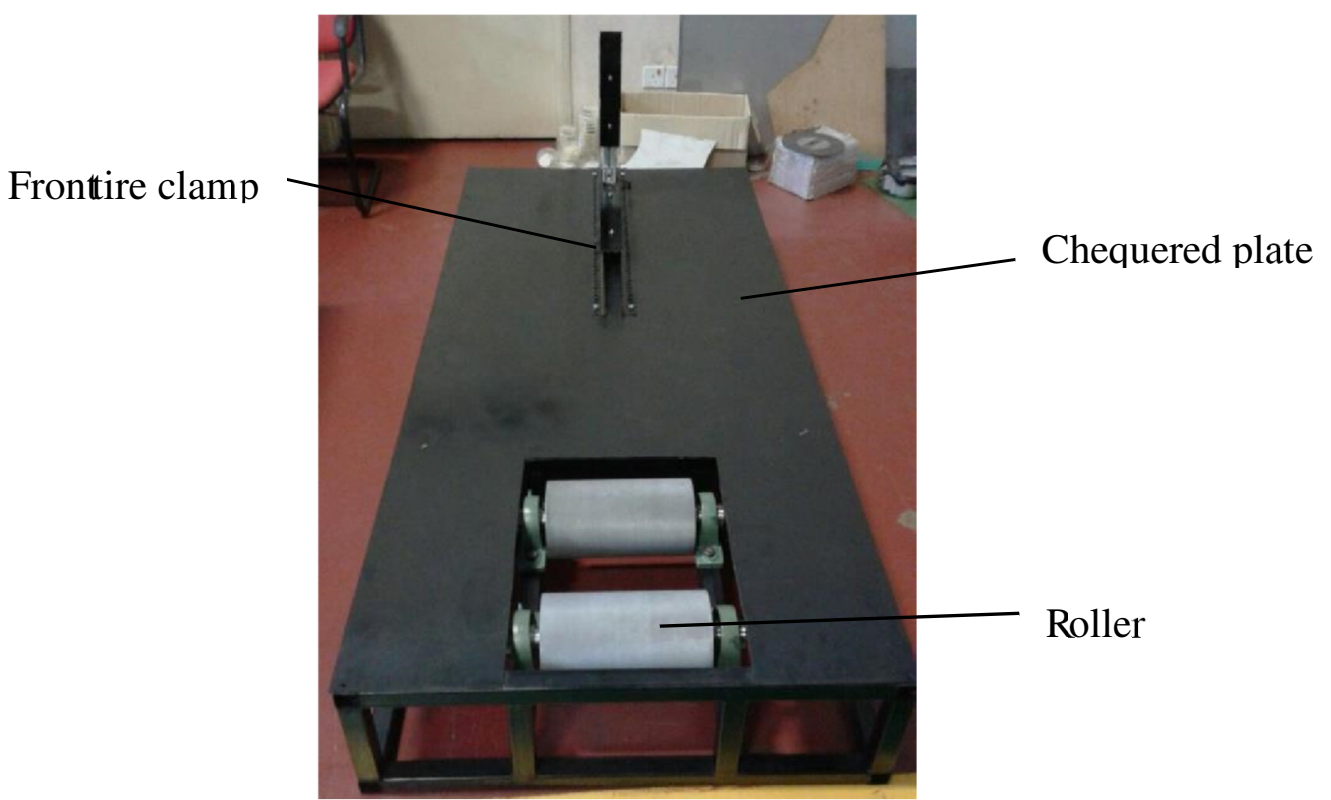

Fig. 2. The basic layout of the prototype of chassis dynamometer built

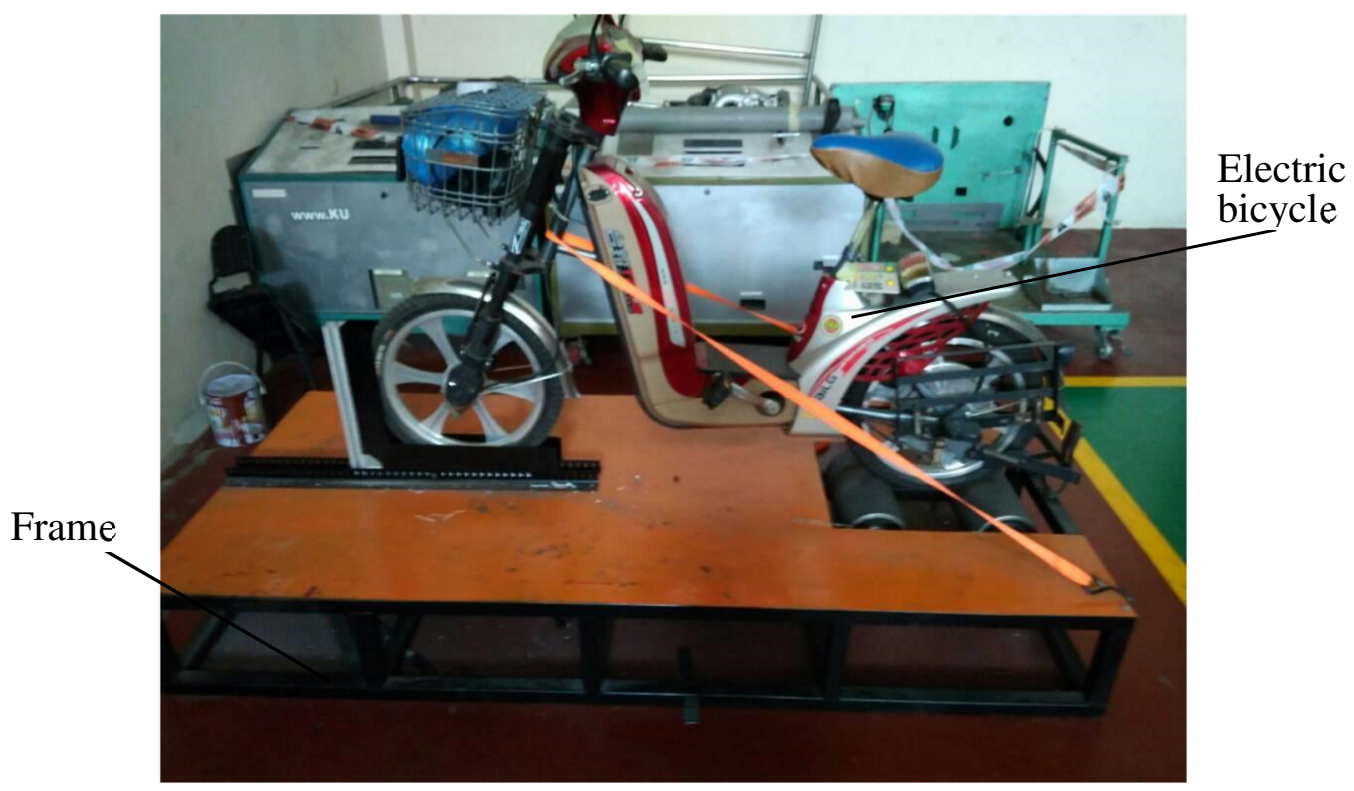

Fig. 3. The prototype of chassis dynamometer 


\section{Commissioning data acquisition system}

This project used sweep test for speed sensing involving rotary encoder and Arduino MEGA 2560 software for data acquisition system in order to cut the cost. The coupling was fitted to the roller and rotary encoder. The load applied was considered including a shaft, the mass of the person operating the vehicle and the mass of the vehicle itself. In this experiment, the rotation of the wheel is not only depending on the supplied rpm but also it is depending on the mass and moment of inertia caused those loads. The electric two-wheeler then was set to the desired rpm. The tires then rotate from static to its maximum rotation and this is important as the principle of sweep test is applied in the test.

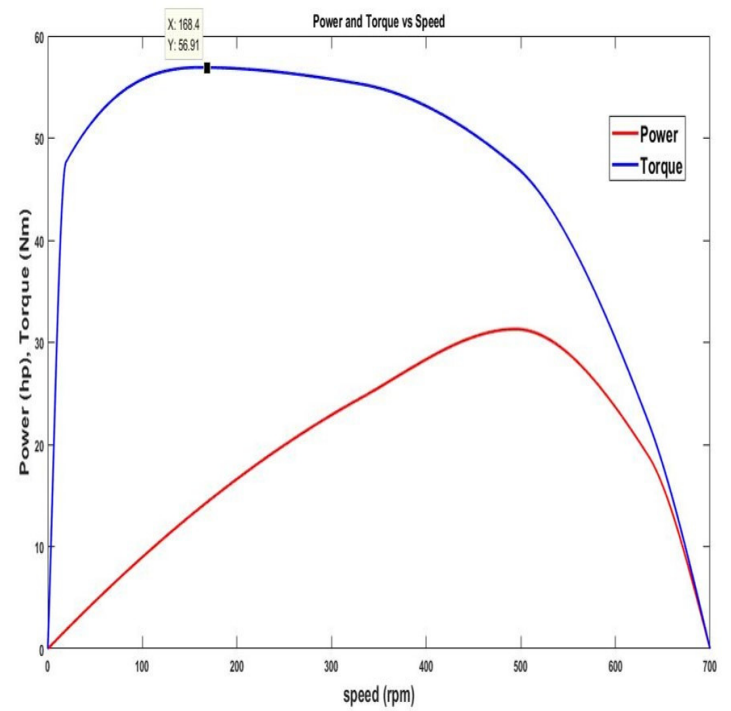

Fig. 4. Power versus RPM and Torque versus RPM graphs

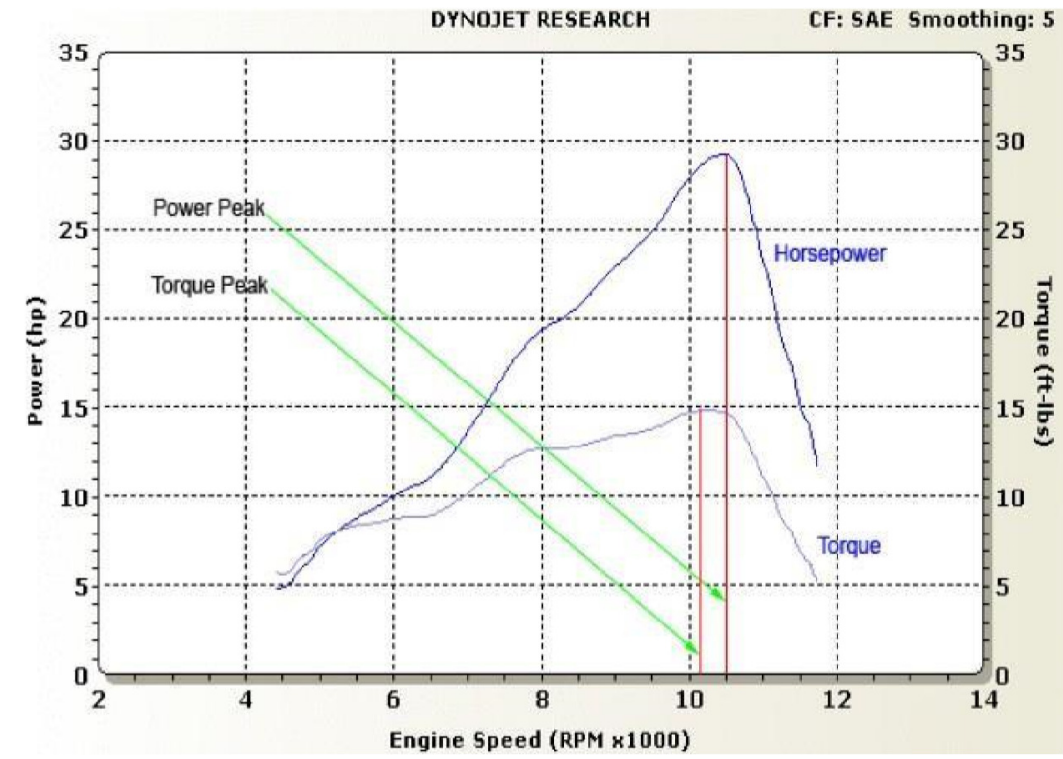

Fig. 5. Theoretical graph of torque/power versus RPM graph [15] 
The graph in figure 4 shows the combination of speed versus time graphs together with torque and power. Data 1, the red line, represent power versus RPM graph. On the other hand, Data 2, the blue line, represents torque versus RPM. The Power graph shows the highest horsepower of the electric two-wheelers is $29 \mathrm{hp}$ at $500 \mathrm{rpm}$. The power of the engine rose rapidly from 0 to $60 \mathrm{rpm}$. And the torque graph shows the highest value at $200 \mathrm{rpm}$. The torque of the engine rises rapidly from 0 to $30 \mathrm{rpm}$. In comparison, the torque reached its peak at $170 \mathrm{rpm}$ whereas the power reached its peak at $500 \mathrm{rpm}$. At the maximum point of torque, the engine's volumetric efficiency is also at the highest. The deviation is observed during testing due to engine recovery from over exhaustion. As validation, figure 4 was compared to the graph from figure 5 which was taken from the literature review. It is shown in figure 5 that the line of torque reaches its maximum value at an early speed while the power will be following at higher speed. Thus, this proves that the results obtained are acceptable.

\section{Conclusions}

Overall, the prototype of chassis dynamometer for electric motorcycle had been developed. The performance of the chassis dynamometer was tested by using an electric bicycle by running it to the top speed. This is to emulate the basic performance requirements of an electric motorcycle which consist of maximum speed, driving range and acceleration.

The authors would like to express their deepest gratitude to the Ministry of Education (FRGS/1/2016/TK03/UMP/02/21 or RDU160139) and University Malaysia Pahang (RDU1603111) for their financial assistance for this project.

\section{References}

1. M. Mendes, G. Duarte, and P. Baptista, Transp. Res. Part C Emerg. Technol. 51, 120-135 (2015).

2. J.-H. Wu, C.-W. Wu, C.-T. Lee, and H.-J. Lee, J. Bus. Res. 68(4), 829-833 (2015).

3. A. A. Juan, C. A. Mendez, J. Faulin, J. De Armas, and S. E. Grasman, Energies 9(2), 1-21 (2016).

4. C. Botsford and A. Szczepanek, Evs24 (May), 1-9 (2009).

5. P. Lombardi, M. Heuer, and Z. Styczynski, IEEE PES Gen. Meet. PES 2010 (August), (2010).

6. K. Aguirre, L. Eisenhardt, C. Lim, B. Nelson, A. Norring, P. Slowik, and N. Tu, PhD Thesis (June), 1-33 (2012).

7. M. Safari, Energy Policy 115, 54-65 (2018).

8. J. S. Gill, P. Bhavsar, M. Chowdhury, J. Johnson, J. Taiber, and R. Fries, Procedia Comput. Sci. 32, 545-552 (2014).

9. W. J. Requia, M. Mohamed, C. D. Higgins, A. Arain, and M. Ferguson, Atmos. Environ. 185, 6477 (2018).

10. L. R. Jones, C. R. Cherry, T. A. Vu, and Q. N. Nguyen, Transp. Res. Part A Policy Pract. 57, 111 (2013).

11. S. Amjad, S. Neelakrishnan, and R. Rudramoorthy, Renew. Sustain. Energy Rev. 14(3), 11041110 (2010).

12. S. Amjad, R. Rudramoorthy, S. Neelakrishnan, K. S. R. Varman, and T. V Arjunan, J. Power Sources 196(6), 3371-3377 (2011).

13. S. Amjad, R. Rudramoorthy, S. Neelakrishnan, K. Sri Raja Varman, and T. V Arjunan, Energy 36(3), 1623-1629 (2011).

14. J. Dinkel, Road \& Track Illustrated Automotive Dictionary (Bentley Publishers, 2000). 